The IJA is a peer-reviewed open-access, electronic journal, freely available without charge to users

Produced by the AquacultureHub non-profit Foundation Sale of $I J A$ papers is strictly forbidden

\title{
Entirely Farm-raised Snubnose Pompano (Trachinotus blochii) Under High Salinity in Saudi Arabia
}

\author{
Benjamin C. Young ${ }^{1,2} *$, Riyadh Hussain Alfaggeh ${ }^{1}$
}

\author{
${ }^{1}$ Jeddah Fisheries Research Center, Ministry of Environment, Water \& Agriculture, Jeddah \\ 21423, Saudi Arabia \\ ${ }^{2}$ Taiwan International Cooperation and Development Fund, Taipei 11047, Taiwan
}

Key words: Snubnose pompano; aquaculture operation; Saudi Arabia; high salinity

\begin{abstract}
Snubnose pompano (Trachinotus blochii), a species of economic importance in the Red Sea region, has shown aquaculture potential in Saudi Arabia. The unique environment of the Red Sea causes aquaculture systems to operate under high salinity $(42 \% 0-45 \%$ ), but there is a lack of information regarding the culture of snubnose pompano in these conditions. This study estimated the survival, growth, and farming costs of snubnose pompano in two production systems: indoor and outdoor tanks. The experiments were performed in triplicate in 2020-2021, with 100 sub-adult fish per production system. The survival rate, growth performance, natural sexual maturation, and farming costs were determined. The results indicated that snubnose pompano culture is feasible under high salinity conditions using the indoor production system considering the significant differences in survival rate and growth performance, although the outdoor system had lower feed and labor costs. After 550 days of rearing, the sub-adult fish weighed more than 1,100-1,200 g, and both males and females had sexually mature gonads. These results show that spawning can be induced in high salinity $(42 \%$ o) conditions. This study was the first to successfully farm-raise snubnose pompano in Saudi Arabia. Our results can thus be used as a reference for related research and aquaculture development in the Middle East region.
\end{abstract}




\section{Introduction}

Fish culture is becoming an essential aspect of aquaculture in Saudi Arabia due to the need for sustainable economic development and food security. Limitations in policies and the natural environment make marine fish culture more suitable in this region than freshwater fish culture (Young et al., 2021a). Currently, the most popular marine aquaculture fish species in Saudi Arabia include Sabaki tilapia (Oreochromis spilurus), Asian sea bass (Lates calcarifer), and gilt-head bream (Sparus aurata). Despite remarkable advances in fish culture since the 2010s, mariculture still faces several hurdles in Saudi Arabia. For instance, overproduction has led to price reductions in Asian sea bass (Young et al. 2020a). In addition, fingerlings of numerous marine fish species depend on imports (Young and AlMoutiri, 2021). Thus, the Saudi fisheries authority continues to promote marine fish species for further aquaculture development.

Of the marine finfish species in the Red Sea region, the snubnose pompano (Trachinotus blochii) is a well-known, highly economically valued species in the global aquaculture industry (Liao et al. 2001; Tesfamichael and Saeed, 2016; Pathak et al.,2019). In 2018 , the global aquaculture production of the snubnose pompano was 2,480 tons (Food and Agriculture Organization of the United Nations, 2021). Malaysia, Singapore, and Brunei are the largest producers of snubnose pompano (Food and Agriculture Organization of the United Nations, 2021). Owing to market demand and environmental factors, the fisheries authority of Saudi Arabia selected the snubnose pompano in 2018 as a target species for aquaculture development projects because commercial culture of the snubnose pompano had not yet been developed in Saudi Arabia. Pompano culture in Saudi Arabia has been confronted with many difficulties, such as extreme salinity. On the Jeddah coastline, West Saudi Arabia, the seawater has a salinity of $42 \%$ o- $45 \%$ during the production period (Saunders et al. 2016; Young et al. 2021a). Additionally, the high cost of freshwater is an important factor that influences the production costs of aquaculture in Saudi Arabia. Regulations strictly prohibit the installation of pumping wells (Elhendy and Alzoom 2001; Young et al. 2020a). Hence, freshwater consumption in most mariculture farms in Saudi Arabia is decreasing (Young and AlMoutiri, 2021).

Recently, Young et al. (2021b) found that pompano larviculture is feasible at salinities of $33 \%$ o-39\% and that the larvae could acclimatize to $42 \%$ salinity 45 days after hatching, with no stunted growth in the grow-out stage. There is a lack of information on the sexual maturity of artificially propagated snubnose pompano under high salinity conditions. Against this background, this study was designed to determine the spawning conditions and period required for snubnose pompano culture under high salinity conditions.

\section{Materials and Methods}

Experimental design. Snubnose pompano were grown from March 20, 2020, to September 21, 2021 at the Jeddah Fisheries Research Center, Jeddah, Saudi Arabia, which was the first successful larviculture of snubnose pompano in Saudi Arabia (Young et al. 2021b). Because snubnose pompano culture in Saudi Arabia currently involves the use of the intensive system, such as recirculating aquaculture system and concrete pond, we used the same culture conditions in this study. The experiments were performed in triplicate in two $20-\mathrm{m}^{3}$ indoor and outdoor concrete pond production systems with 100 sub-adult snubnose pompano per system. The average weight of the fish was $50.7 \pm 1.65 \mathrm{~g}$ without separating the sexes on March 20, 2020.

The frequency, quantity of feed, and feeding competition were controlled manually. Commercial feed (sinking, $6 \mathrm{~mm}, 45 \%$ crude protein, 12\% crude fat; Arasco, Saudi Arabia) was fed to the fish daily at $5 \%$ body weight. Throughout the study period, the fish were hand-fed twice daily at 8:00 and 14:00 h. The feeding trials and pond management methods used were adopted from a previous record of broodstock management of snubnose pompano by Young et al. (2021b). 
The daily water exchange and Knudsen water salinity in the production systems were $10 \%$ and $42 \%-45 \%$, respectively. The temperature ranged from $22.3^{\circ} \mathrm{C}$ to $42.0^{\circ} \mathrm{C}$, with $\mathrm{a} \mathrm{pH}$ of $5.27-7.30$ and a dissolved oxygen (DO) content of $4.80-6.10 \mathrm{mg} / \mathrm{L}$ in both production systems. Dead fish, uneaten feed, and fecal matter were removed twice daily. The fish were sampled once every $30 \mathrm{~d}$ to determine the survival rate, growth performance, and production operating costs. When the weight of the sampled fish was $>1,000 \mathrm{~g}$, the suction curette (3.0 mm, PANPAC, Taiwan) was used to determine ovigerousness.

The survival rate was calculated as follows: number of survivors at the end of the experiment $\times 100 /$ initial number stocked. The specific growth rate was determined using the following equation: specific growth rate (\% body weight per day) $=[($ In (W2 W1) $\times 100] / \Delta t$, where W1 represents the initial wet fish weight at stocking, W2 represents the final wet fish weight, and $t$ represents the grow-out period. The feed conversion ratio (FCR) was determined by feed weight/fish weight gain.

Monetary amounts (USD [\$]) were used to determine the cost distribution of each fish production system.

Statistical analyses. The results were analyzed using Predictive Analytics Software version 18.0 (IBM, Armonk, New York) using analysis of variance and Duncan's multiple range test for post hoc comparison of the means. $P<0.05$ was considered significant.

\section{Results}

At the maximum salinity ( $45 \%$ ), the fish survival and growth rate were significantly higher in the indoor system than in the outdoor system $(P<0.05)$ (Table 1). The most effective production system was the indoor system, with the highest survival rate and gonad maturity of the two systems (Table 1). The survival rate between the systems was significantly different throughout the study period $(P<0.05)$ and were significantly lower in the outdoor system $(P<0.05)$ (Table 1). The outdoor system had lower feed and labor costs than the indoor system; however, the outdoor system had higher variable operating costs (drugs, utilities, maintenance, equipment, pond preparation, and part-time labor) than the indoor system (Table 2). Furthermore, on day 550, periodic observations confirmed that females and males had reached maturity in the indoor system.

Table 1 Survival rate, growth performance, and sexual maturation of snubnose pompano in each production system

\begin{tabular}{|c|c|c|c|c|c|c|}
\hline System & $\begin{array}{l}\text { Survival rate } \\
(\%)\end{array}$ & $\begin{array}{l}\text { Initial weight } \\
\text { (g) }\end{array}$ & $\begin{array}{l}\text { Final weight } \\
\text { (g) }\end{array}$ & $\begin{array}{l}\text { Feed } \\
\text { conversion } \\
\text { ratio }\end{array}$ & $\begin{array}{l}\text { Specific } \\
\text { growth rate }\end{array}$ & $\begin{array}{l}\text { Maturity of } \\
\text { gonads }\end{array}$ \\
\hline Indoor tank & $97.3 \pm 2.5^{a}$ & $50.7 \pm 1.65$ & $\begin{array}{l}1542.6 \pm \\
282^{a}\end{array}$ & $1.61 \pm 0.05^{a}$ & $2.71 \pm 0.11^{a}$ & full maturity \\
\hline $\begin{array}{l}\text { Outdoor } \\
\text { tank }\end{array}$ & $60.0 \pm 8.7^{b}$ & $50.7 \pm 1.65$ & $444 \pm 57.3^{b}$ & $7.44 \pm 0.45^{b}$ & $\begin{array}{l}0.716 \pm \\
0.05^{b}\end{array}$ & immature \\
\hline
\end{tabular}

In each column, different letters indicate a significant difference $(P<0.05)$.

Table 2 Culture costs of snubnose pompano in each production system from March 20, 2020, to September 21, 2021 (USD [\$])

System $\quad$ Feed $\quad$ Labor $\quad$ Operating costs Depreciation

\begin{tabular}{ccccc}
\hline Indoor tank & $\$ 806.11$ & $\$ 155.20$ & $\$ 33.72$ & $\$ 34.26$ \\
Outdoor tank & $\$ 752.64$ & $\$ 132.7$ & $\$ 90.35$ & $\$ 29.54$ \\
\hline
\end{tabular}

Operating costs include costs of drugs, utilities, maintenance, equipment, pond preparation, and part-time labor.

\section{Discussion}

The results of this study showed that spawning of sub-adult snubnose pompano could be induced after 550 days of rearing in high salinity (42\%o) conditions and that they weighed more than 1,200 g. Gopakumar et al. (2012) and Reyes et al. (2014) reported that sub- 
adult snubnose pompano displayed induced spawning after 1 year of rearing in $33 \%$ o general salinity and weighed more than $1.000-1,750 \mathrm{~g}$. Young et al. (2021b) showed that snubnose pompano broodstock could already spawn naturally under high salinity (42\%o) conditions and that they weighed more than $2,500 \mathrm{~g}$. They also noted that in the comparison of feeding with commercial feed and trash fish, the quality of the fertilized egg and the spawning period displayed no significant differences. Considerable variations in water quality parameters (temperature, $\mathrm{DO}$, and $\mathrm{pH}$ ) were not observed between the two systems when the water source and climate were relatively stable.

Our results are consistent with those of several other studies. In the present study, the growth performance for FCR was 1.61 in the indoor system and 7.44 in the outdoor system. Salama (2008), Chithambaran (2019), and Young et al. (2021b) reported that the FCR of outdoor Asian sea bass and Sabaki tilapia farming in Saudi Arabia was 1.48-2.0 in high salinity conditions. Similarly, Hajirezaee et al. (2014) reported that the average FCR was 2.0-2.5 in the Middle East region of Asian sea bass farming.

The higher FCR and lower survival rate in the outdoor system were likely caused by increased stress levels in the fish due to other aquaculture operation activities and the farming environment, which places fish under high salinity (42\%o-45\%o) and temperature stress $\left(37^{\circ} \mathrm{C}-45^{\circ} \mathrm{C}\right)$ conditions (Saunders et al. 2016; Young et al. 2021a). Hence, diseases, especially parasitic and bacterial infections, frequently occur in mariculture in the winter. Al-Harbi and Uddin (2006) and Young et al. (2021a) reported that during the winter season, i.e., in temperatures of $<25^{\circ} \mathrm{C}$, disease, bacterial infection in particular frequently occurs in outdoor farming systems in Saudi Arabia. Moreover, Cruz and Ridha (1990) found that low water temperature reduced the growth performance of sea cage farming in the Middle East. In agreement with related research, we found that the intensive sea cage system is unsuitable for snubnose pompano farming in winter, with stress conditions and higher risk of fish diseases due to aquaculture operation activities. Furthermore, we noted that diseases such as bacterial and parasitic infection are frequent in both indoor and outdoor farming systems of snubnose pompano in Saudi Arabia during the winter season.

Our results also showed that feed and labor were the major cost-related factors in snubnose pompano farming, which was consistent with the mariculture results reported in Saudi Arabia by Young et al. (2020b, 2021a). Most aquaculture companies in Saudi Arabia are either industrial or large-scale businesses. In developing countries, this is important because the scale of farming operations makes a significant difference. For example, Young et al. (2021c) reported that industrial-scale producers spent less on feed in Saudi Arabia because they could produce feed at their own facilities. In contrast, Zhang et al. (2016) found that small-scale Chinese fish producers were economically inefficient. Furthermore, Young and AlMoutiri (2021) reported that limiting environmental factors and higher-cost production facilities were more common in fish farming in Saudi Arabia.

This research was the first to successfully farm-raise snubnose pompano in Saudi Arabia. Our results can used as a reference for further research and aquaculture development in the Middle East region.

\section{Acknowledgements}

The authors thank the Jeddah Fisheries Research Center, Saudi Arabia, for providing all material.

\section{References}

Al-Harbi, A. H., \& Uddin, M. N., 2006. Seasonal changes in bacterial flora of fish pond sediments in Saudi Arabia. Journal of Applied Aquaculture 18: 35-45. https://doi.org/10.1300/J028v18n02 03

Chithambaran, S., 2019. Growth and predator-prey interaction of Asian seabass, Lates calcarifer and Sabaki tilapia, Oreochromis spilurus in Polyculture System. Thalassas 35: 215-221. https://doi.org/10.1007/s41208-018-0112-z 
Cruz, E. M., \& Ridha M., 1990. Production of marketable-size tilapia, Oreochromis spilurus (Günther), in seawater cages using different production schedules. Aquaculture Research 21:187-194. https://doi.org/10.1111/j.1365-2109.1990.tb00456.x

Elhendy, A. M., \& Alzoom, A. A., 2001. Economics of fish farming in Saudi Arabia: Analysis of costs of tilapia production. Aquaculture Economics and Management 5: 229238. https://doi.org/10.1080/13657300109380289

Food and Agriculture Organization of the United Nations, 2021. Global aquaculture production. Food and Agriculture Organization of the United Nations, Rome. Available: http://www.fao.org/fishery/statistics/global-aquaculture-production/query/en. (October 2021)

Gopakumar, G., Nazar, A. A., Jayakumar, R., Tamilmani, G., Kalidas, C., Sakthivel, M., Rameshkumar, P., Hanumanta Rao, G., Premjothi, R., Balamurugan, V., Ramkumar, B., Jayasingh, M., \& Syda Rao, G., 2012. Broodstock development through regulation of photoperiod and controlled breeding of silver pompano, Trachinotus blochii (Lacepede, 1801) in India. Indian Journal of Fisheries 59: 53-57.

Liao, I. C., Su, H. M., \& Chang, E. Y., 2001. Techniques in finfish larviculture in Taiwan. Aquaculture 200: 1-31. https://doi.org/10.1016/S0044-8486(01)00692-5

Pathak, M. S., Lakra, W. S., Reddy, A. K., Chadha, N. K., Tiwari, V. K., \& Srivastava, P. P., 2019. Growth and survival of silver pompano Trachinotus blochii (Lacepede, 1801) at different salinities in inland saline ground water. Indian Journal of Animal Sciences 89: 581-587.

Reyes, O. S., de Jesus-Ayson, E. G. T., Pedroso, F. L., \& Cabanilla, M. I. C., 2014. Hatchery production of snubnose pompano Trachinotus blochii Lacepede. Aquaculture Department, Southeast Asian Fisheries Development Center, Philippines.

Salama, A. J., 2008. Effects of different feeding frequency on the growth, survival and feed conversion ratio of the Asian sea bass Lates calcarifer juveniles reared under hypersaline seawater of the Red Sea. Aquaculture Research 39: 561-567. https://doi.org/10.1111/j.1365-2109.2007.01890

Saunders, J. F., Cardia, M. S., Hazzaa, B., Rasem, M. A., Othaibi, M. I., \& Rafiq, M. B., 2016. Atlas of potential areas for cage aquaculture: Red Sea - Kingdom of Saudi Arabia. Food and Agriculture Organization of the United Nations, UTF/SAU/048/SAU, Rome, Italy. Tesfamichael, D., \& Saeed, H., 2016. Common names of exploited fish and invertebrates of the Red Sea. pp. 135-190. In: D. Tesfamichael, D. Pauly (eds.). Coral reefs of the world, 7. Springer. https://doi.org/10.1007/978-94-017-7435-2 10

Young, B. C., Alfaggeh, R. H., \& AlMoutiri, I., 2020a. Larviculture of Snubnose pompano Trachinotus blochii in the Kingdom of Saudi Arabia. World. Aquaculture 51: 5052.

Young, B. C., Alfaggeh, R. H., AlMoutiri, I., \& Lee, P. P., 2020b. Status and cost analysis of Asian sea bass aquaculture operations in the Kingdom of Saudi Arabia. Journal of the Fisheries Society of Taiwan 47: 234-242. https://doi.org/10.29822/JFST.202012 47(4).0005

Young, B. C., Alfaggeh, R. H., \& AlMoutiri, I., 2021a. Growth, fry production, and cost analysis for Sabaki tilapia production systems. North American Journal of Aquaculture 83: 290-293. https://doi.org/10.1002/naaq.10189

Young, B. C., Alfaggeh, R. H., \& AlMoutiri, I., 2021b. Larviculture of Snubnose Pompano under conditions of high salinity. North American Journal of Aquaculture 83: 3840. http://doi.org/10.1002/naaq.10173

Young, B. C., Alfaggeh, R. H., \& AlMoutiri, I., 2021c. Status and cost analysis of Sabaki tilapia farming in Saudi Arabia. Aquaculture International 29: 871-878. https://doi.org/10.1007/s10499-021-00663-z

Young, B. C., \& AlMoutiri, I., 2021. Effects of high salinity on the larviculture of Asian sea bass Lates calcarifer in outdoor systems. North American Journal of Aquaculture. https://doi.org/10.1002/naaq.10222 
Zhang, Z., Zhang, Y., Li, F., Yang, H., Yuan, Y., \& Yuan, X., 2016. Economic efficiency of small-scale tilapia farms in Guangxi, China. Aquaculture, Economics and Management 21: 283-294. https://doi.org/10.1080/13657305.2016.1180644 